\title{
Effects of Antibodies against Cell Surface Protein Antigen PAc-Glucosyltransferase Fusion Proteins on Glucan Synthesis and Cell Adhesion of Streptococcus mutans
}

\author{
HAO YU, YOSHIO NAKANO, YOSHIHISA YAMASHITA, TAKAHIKO OHO, \\ AND TOSHIHIKO KOGA* \\ Department of Preventive Dentistry, Kyushu University \\ Faculty of Dentistry, Fukuoka 812-82, Japan
}

Received 3 September 1996/Returned for modification 11 October 1996/Accepted 31 March 1997

\begin{abstract}
Cell surface protein antigen (PAc) and glucosyltransferases (GTFs) produced by Streptococcus mutans are considered to be major colonization factors of the organism, and the inhibition of these two factors is predicted to provide protection against dental caries. In this study, we have constructed fusion protein PAcA-GB, a fusion of the saliva-binding alanine-rich region (PAcA) of PAc with the glucan binding (GB) domain of GTF-I, an enzyme catalyzing the synthesis of water-insoluble glucan from sucrose, and fusion protein PAcA-SB, a fusion of PAcA with the sucrose binding (SB) domain of GTF-I. The recombinant fusion proteins were purified from cell extracts of Escherichia coli harboring the fusion genes, and rabbit antibodies against these fusion proteins were prepared. Water-insoluble glucan synthesis by cell-associated and cell-free GTF preparations from $S$. mutans as well as total glucan synthesis by GTF-I was markedly inhibited by anti-PAcA-GB immunoglobulin G (IgG) antibodies but not by anti-PAcA-SB IgG antibodies. Significant inhibition of the sucrose-independent and sucrose-dependent adhesion of $S$. mutans to saliva-coated hydroxyapatite beads was observed when anti-PAcA-GB antibodies were added to the reaction mixture. Anti-PAcA-SB antibodies inhibited the adhesion of $S$. mutans to the beads in the absence of sucrose but not in the presence of sucrose. Immunization with the fusion protein PAcA-GB may be useful for controlling the colonization of teeth by $S$. mutans.
\end{abstract}

Streptococcus mutans has been strongly implicated as a causative organism of dental caries (30). Colonization of tooth surfaces by these microorganisms is considered to be the first important step for the induction of dental caries. This process is mediated by sucrose-independent and sucrose-dependent mechanisms $(17,19)$. The former mechanism is the interaction between $S$. mutans and acquired pellicles on tooth surfaces (18). The latter is due to the synthesis of water-insoluble glucan from sucrose catalyzed by glucosyltransferases (GTFs) (20).

S. mutans possesses various cell surface polymers such as wall-associated proteins, serotype-specific antigens, lipoteichoic acid, and peptidoglycan. Among these polymers, a 190$\mathrm{kDa}$ cell surface protein antigen, variously designated as antigen I/II, B, IF, P1, SR, MSL-1, or PAc (29), is known to be one of the factors that mediate the binding of the organism to salivary components on tooth surfaces $(3,18,23)$. The PAc protein possesses two internal repeating amino acid sequences: one sequence located in the $\mathrm{N}$ terminus is rich in alanine (A region), while the other, located in the middle portion, is rich in proline (P region) $(15,28)$. The $\mathrm{N}$-terminal portion including the A region is considered to be one of the important domains which interact with salivary receptors on tooth surfaces $(4,7,12,27)$. The protein antigen has been given much attention as a possible dental caries vaccine $(24,29)$.

$S$. mutans produces both water-soluble and water-insoluble glucans from sucrose by the combined action of three forms of

\footnotetext{
* Corresponding author. Mailing address: Department of Preventive Dentistry, Kyushu University Faculty of Dentistry, 3-1-1 Maidashi, Higashi-ku, Fukuoka 812-82, Japan. Phone: 81-92-642-6350. Fax: 8192-642-6354. E-mail: toshidha@mbox.nc.kyushu-u.ac.jp.
}

GTF (GTF-I, GTF-SI, and GTF-S) (20). De novo synthesis of water-insoluble glucan allows $S$. mutans to tenaciously adhere and accumulate on tooth surfaces. These enzymes are highly homologous proteins of approximately 1,500 residues organized into two relatively independent structural and functional domains: an N-terminal sucrose binding (SB) domain and a C-terminal glucan binding (GB) domain (20). Among these GTFs, GTF-S synthesizes water-soluble glucan from sucrose. On the other hand, GTF-I and GTF-SI synthesize primarily water-insoluble glucan.

The important roles of PAc and GTF-I in cariogenicity of $S$. mutans make them rational targets for the development of an anticaries vaccine and an adhesion inhibitor. Simultaneous inhibition of these colonization factors may result in the protection of teeth from dental caries. In this study, we constructed fusion protein PAcA-GB, a fusion of the saliva binding A region (PAcA) of PAc with the GB domain of GTF-I, and fusion protein $\mathrm{PAcA}: \mathrm{SB}$, a fusion of $\mathrm{PAcA}$ with the $\mathrm{SB}$ domain of GTF-I. In addition, the inhibitory effects of antibodies against the fusion proteins on glucan synthesis by GTFs from $S$. mutans and the in vitro adhesion of the organism to salivacoated hydroxyapatite (S-HA) in the absence or presence of sucrose are discussed.

\section{MATERIALS AND METHODS}

Bacteria. The bacterial strains used in this study are listed in Table 1. The media used were L broth and $2 \times$ TY broth (22) for Escherichia coli and brain heart infusion (BHI; Difco Laboratories, Detroit, Mich.) and Todd-Hewitt broth (Difco Laboratories) for $S$. mutans.

Reagents. [Glucose- $\left.6-{ }^{3} \mathrm{H}\right]$ sucrose and $\left[\right.$ methyl $\left.-{ }^{3} \mathrm{H}\right]$ thymidine were purchased from American Radiolabeled Chemicals Inc. (St. Louis, Mo.). Alkaline phosphatase-conjugated goat anti-rabbit immunoglobulins, 5-bromo-4-chloro-3-indolylphosphate, and nitroblue tetrazolium were purchased from Sigma Chemical Co. (St. Louis, Mo.). Restriction endonucleases were supplied by New England 
TABLE 1. Bacterial strains

\begin{tabular}{|c|c|c|}
\hline Strain & Description & $\begin{array}{l}\text { Reference or } \\
\text { source }\end{array}$ \\
\hline \multicolumn{3}{|l|}{ S. mutans } \\
\hline MT8148 & Serotype c, $p a c^{+} g t f B^{+} g t f C^{+} g t f D^{+} f t f^{+}$ & 18 \\
\hline TK-18 & 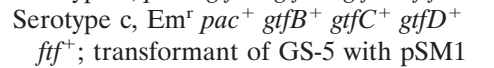 & 18 \\
\hline UA130 & Serotype c, $p a c^{+} g t f B^{+} g t f C^{+} g t f D^{+} f t f^{+}$ & 37 \\
\hline UA130B & $\begin{array}{l}\text { Serotype c, } \mathrm{Em}^{\mathrm{r}} \text {; transformant of UA130; } \\
\quad \text { pac }^{+} \text {gtfB gtfC } C^{+} \text {gtfD } \mathrm{ftf}^{+}\end{array}$ & 37 \\
\hline UA130C & $\begin{array}{l}\text { Serotype c, Em }{ }^{\mathrm{r}} \text {; transformant of UA130; } \\
\text { pac }^{+} \text {gtfB } B^{+} \text {gtfC } g t f D^{+} \mathrm{ftf}^{+}\end{array}$ & 37 \\
\hline UA130BC & $\begin{array}{l}\text { Serotype c, } \mathrm{Em}^{\mathrm{r}} ; \text { transformant of UA130; } \\
\quad \text { pac }^{+} \text {gtfB gtfC } g t f D^{+} \mathrm{ft}^{+}\end{array}$ & 37 \\
\hline $\mathrm{UA} 130 \mathrm{~B}^{+}$ & $\begin{array}{l}\text { Serotype c; } \mathrm{Em}^{\mathrm{r}} \mathrm{Te}^{\mathrm{r}} \mathrm{Sm}^{\mathrm{r}} \text {; transformant of } \\
\quad \text { UA130C; } p a c^{+} \text {gtf } B^{+} \text {gtfC gtfD ftf }\end{array}$ & This study \\
\hline $\mathrm{UA} 130 \mathrm{C}^{+}$ & $\begin{array}{l}\text { Serotype c; } \mathrm{Em}^{\mathrm{r}} \mathrm{Te}^{\mathrm{r}} \mathrm{Sm}^{\mathrm{r}} \text {; transformant of } \\
\quad \text { UA130B; pac }{ }^{+} \text {gtfC }^{+} \text {gtfB gtfD ftf }\end{array}$ & This study \\
\hline $\mathrm{UA} 130 \mathrm{D}^{+}$ & $\begin{array}{l}\text { Serotype c; } \mathrm{Em}^{\mathrm{r}} \mathrm{Sm}^{\mathrm{r}} ; \text { transformant of } \\
\quad \text { UA130BC; } \text { ac }^{+} \text {gtfD }^{+} \text {gtfB gtfC ftf }\end{array}$ & This study \\
\hline \multicolumn{3}{|l|}{ E. coli } \\
\hline HB101 & $\begin{array}{l}\left.\text { supE44 hsdS2O( } \mathrm{r}_{\mathrm{B}}{ }^{-} \mathrm{m}_{\mathrm{B}}{ }^{-}\right) \text {recA13 ara-14 } \\
\text { proA2 lacY1 galK2 rpsL20 xyl-5 mtl-1 }\end{array}$ & Nippon Gene \\
\hline XL1-Blue & $\begin{array}{l}\text { supE44 hsdR17 recA1 endA1 gyrA46 thi } \\
\text { relA1 lac } \mathrm{F}^{\prime}\left[\text { proAB } \text { lacI }^{\mathrm{q}} \text { lacZ } \Delta M 15\right. \\
\left.\text { Tn10 }\left(\text { Tet }^{\mathrm{r}}\right)\right]\end{array}$ & Stratagene \\
\hline DH5 & $\begin{array}{l}\text { supE44 hsdR17 recA1 endA1 gyrA96 thi-1 } \\
\text { relA1 }\end{array}$ & Nippon Gene \\
\hline
\end{tabular}

Biolabs Inc. (Beverly, Mass.) and Takara Shuzo Co. (Ohtsu, Japan). A Qiagen kit for protein expression and purification was purchased from Qiagen Inc. (Chatsworth, Calif.). An Affi-Gel protein A MAPS II kit for antibody purification was purchased from Bio-Rad Laboratories (Richmond, Calif.). The other reagents were of the highest purity commercially available.

Construction of fusion proteins and truncated GTF-I fragments. Isolation of chromosomal DNA from $S$. mutans and transformation of $S$. mutans were performed as previously described (18). The $15-\mathrm{kb} S p h \mathrm{I}$ fragment containing the intact $g t f C$ gene and truncated $g t f B$ gene from $S$. mutans MT8148 was isolated by using the gtfB fragment (bp 2336 to 3006) of $S$. mutans GS-5 (33) as a probe. The BstEII-SnaBI fragment encoding the GB domain (GTF-I-GB; amino acid residues 1083 to 1475 ) was inserted into pBluescript II to create pBlueGB. The gene fragment encoding the SB domain (GTF-I-SB; amino acid residues 266 to 529) was amplified by PCR with the specific primers (5' TTCCGTCCCTTATTGATG $3^{\prime}$ and $5^{\prime}$ TGAACGTTGATTTAAGGG $3^{\prime}$ ) and subcloned into pBluescript II to create pBlueSB. The gene fragment encoding PAcA (amino acid residues 200 to 481) was amplified by PCR as previously described (27). The gene fragments $g t f B-G B$ and $g t f B-S B$ were digested with SalI and $S m a I$ and then inserted into plasmid pACA202 (a pTrc99A [1] derivative containing the pacA fragment) to construct the fusion genes and create pFPG22 and pFPG23, respectively. Finally, the two fusion genes were digested with $\mathrm{KpnI}$ and $\operatorname{Sma\mathrm {I}}$ and inserted into the expression plasmid $\mathrm{pQE}-30$ at appropriate cloning sites to create plasmids pQEPG22 and pQEPG23 as summarized in Fig. 1. To construct the plasmids which produce GTF-I-GB and GTF-I-SB, the gene fragments $g t f B-G B$ and $g t f B$ $S B$, respectively, were subcloned into $\mathrm{pQE}-30$ at appropriate sites in the vector. The plasmids containing the gtfB-GB fragment and the gtfB-SB fragment were designated pQEGB and pQESB, respectively.

Expression and purification of fusion proteins. For expressing and purifying the fusion proteins, plasmids pQEPG22 and pQEPG23 were transformed into $E$. coli XL1-Blue. The transformants were incubated overnight at $37^{\circ} \mathrm{C}$ in $2 \times \mathrm{TY}$ broth containing $200 \mu \mathrm{g}$ of ampicillin per $\mathrm{ml}$ and $2 \%$ glucose. The cultures were diluted 1:20 with the fresh medium and grown at $37^{\circ} \mathrm{C}$ until an $A_{550}$ of 1.0 was attained. Isopropyl- $\beta$-D-thiogalactopyranoside was added to the cultures at a final concentration of $1 \mathrm{mM}$, and the cultures were grown for 3 to $4 \mathrm{~h}$. The cells were harvested by centrifugation at $1,600 \times g$ for $20 \mathrm{~min}$ at $4^{\circ} \mathrm{C}$ and washed with phosphate-buffered saline (PBS). One-step purification of the fusion proteins with a Qiagen kit was performed according to the manufacturer's directions. In brief, the cell pellet was solubilized in $5 \mathrm{ml}$ of buffer A (6 M guanidine- $\mathrm{HCl}, 0.1$ $\mathrm{M}$ sodium phosphate, $0.01 \mathrm{M}$ Tris- $\mathrm{HCl}, \mathrm{pH} 8.0$ ) per $\mathrm{g}$ (wet weight) and mixed by inversion for $1 \mathrm{~h}$ at $4^{\circ} \mathrm{C}$. The lysate was centrifuged at $10,000 \times g$ for $15 \mathrm{~min}$ at $4^{\circ} \mathrm{C}$, and the supernatant was applied to a Ni-nitrilotriacetic acid resin column $(1.0$ by $10 \mathrm{~cm}$ ) containing $2 \mathrm{ml}$ of resin equilibrated with buffer A. The column was extensively washed with buffer $\mathrm{A}$ and then with more than 5 volumes of buffer B ( $8 \mathrm{M}$ urea, $0.1 \mathrm{M}$ sodium phosphate, $0.01 \mathrm{M}$ Tris- $\mathrm{HCl}, \mathrm{pH}$ 8.0) until the
$A_{280}$ of eluant was less than 0.01 . The column was further washed with buffer $\mathrm{C}$ ( $8 \mathrm{M}$ urea, $0.1 \mathrm{M}$ sodium phosphate, $0.01 \mathrm{M}$ Tris- $\mathrm{HCl}, \mathrm{pH}$ 6.3) until the $A_{280}$ of eluant was less than 0.01 . The fusion proteins were eluted with buffer $\mathrm{C}$ containing $250 \mathrm{mM}$ imidazole. The purified fusion proteins were analyzed by sodium dodecyl sulfate-polyacrylamide gel electrophoresis (SDS-PAGE) followed by immunoblotting.

Preparation of GTFs and GTF-I fragments. Cell-free and cell-associated GTFs were prepared as described by Hamada et al. (13). In brief, $S$. mutan strains were grown in BHI broth for $18 \mathrm{~h}$ at $37^{\circ} \mathrm{C}$. Cell-free GTF was prepared from supernatants of $S$. mutans cultures. Cell-associated GTF was extracted from whole cells of $S$. mutans by treatment with $8 \mathrm{M}$ urea at $25^{\circ} \mathrm{C}$ for $1 \mathrm{~h}(13)$. The extract was dialyzed against $10 \mathrm{mM}$ sodium phosphate buffer $(\mathrm{pH} 6.0)$ and centrifuged, and the supernatant was used as the cell-associated GTF preparation. To examine the effects of antibodies on each GTF of S. mutans, transformants producing a single species of GTF were constructed. S. mutans transformants UA130B, UA130C, and UA130BC, which are defective in the gtfB gene product (GTF-I), the gtfC gene product (GTF-SI), and both the gtfB and $g t f C$ gene products, respectively, were kindly supplied by $\mathrm{H}$. K. Kuramitsu (State University of New York, Buffalo) (37). Strains UA130B and UA130C were successively transformed with linearized pNH5TET (14) to inactivate the gtfD gene and with linearized $\mathrm{pResAmpdFTFSp}{ }^{\mathrm{r}}$ to delete the fructosyltransferase $(f t f)$ gene. (The $f t f$ gene was inactivated to rule out the possibility that fructosyltransferase might utilize sucrose as a substrate in the GTF assay.) pResAmpd FTFSp $^{\mathrm{r}}$ is equivalent to pResAmpdFTFKm ${ }^{\mathrm{r}}$ constructed by Shiroza and Kuramitsu (32) except that the kanamycin resistance gene is replaced with the spectinomycin resistance gene. The transformant which produced only GTF-SI was designated $\mathrm{UA} 130 \mathrm{C}^{+}$, and that which produced only GTF-I was designated $\mathrm{UA} 130 \mathrm{~B}^{+}$. Strain UA130BC was transformed with linearized pResAmpdFTFSp ${ }^{\mathrm{r}}$ to delete the $\mathrm{ftf}$ gene. The transformant which produced only GTF-S (the gtf gene product) was designated UA130 ${ }^{+}$. The appropriate construction of each strain was confirmed by Southern blot analysis as well as immunoblot analysis with rabbit anti-GTF-I serum and antifructosyltransferase serum. GTF-S was prepared from culture supernatants of the transformant UA130D ${ }^{+}$. GTF-I and GTF-SI were extracted from whole cells of the transformants $\mathrm{UA} 130 \mathrm{~B}^{+}$and $\mathrm{UA} 130 \mathrm{C}^{+}$by treatment with $8 \mathrm{M}$ urea at $25^{\circ} \mathrm{C}$ for $1 \mathrm{~h}$. The GTF-I preparation extracted from whole cells of the transformant $\mathrm{UA} 130 \mathrm{~B}^{+}$was purified by affinity chromatography. Briefly, anti-PAcA-SB immunoglobulin G (IgG) antibodies (5 $\mathrm{mg}$ ) prepared as described below were coupled to $3.5 \mathrm{ml}$ of $\mathrm{CNBr}$-activated Sepharose 4B (Pharmacia, Uppsala, Sweden) according to the manufacturer's instructions. The cell extract was mixed gently with the antibody-coupled gel in binding buffer ( $100 \mathrm{mM} \mathrm{KCl}, 3 \mathrm{mM} \mathrm{NaCl}, 3.5 \mathrm{mM} \mathrm{MgCl}, 1.25 \mathrm{mM}$ EGTA, 10 $\mathrm{mM}$ HEPES, $\mathrm{pH}$ 7.3) for $1 \mathrm{~h}$ at room temperature. The gel was packed in a column and washed extensively with the binding buffer followed by washing with $0.1 \%$ Triton X-100. GTF-I was eluted with elution buffer $(0.1 \%$ Triton X-100, 50 $\mathrm{mM}$ glycine, $\mathrm{pH}$ 2.5).

To prepare GTF-I-GB and GTF-I-SB, plasmids pQEGB and pQESB, respectively, were transformed into $E$. coli XL1-Blue. Both GTF fragments extracted from the transformants were purified with a Qiagen kit as described above for purification of the PAc-GTF fusion proteins.

Preparation of antibodies. Antisera to the purified fusion proteins and GTF-I were raised in female Japanese White rabbits (Seiwadoubutsu Co., Fukuoka, Japan) as previously described (18). Rabbits were immunized intramuscularly with $500 \mu \mathrm{g}$ of the purified protein emulsified in Freund's complete adjuvant (Difco Laboratories), followed 2 weeks later by intramuscular injection of $250 \mu \mathrm{g}$ of the same protein emulsified in Freund's incomplete adjuvant (Difco Laboratories). Blood was collected 2 weeks after the last immunization. IgG antibodies against the fusion proteins were purified from the rabbit sera with an Affi-Gel protein A MAPS II kit. Specificity of the purified antibodies was analyzed by immunoblotting. Recombinant PAc and PAcA polypeptides were extracted and

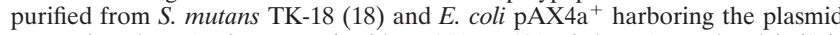
expressing the PAc fragment (residues 200 to 481 of the PAc molecule) (27), respectively. Rabbit antibodies against $\mathrm{rPAc}$ and PAcA were also raised and purified as described above.

GTF assay. Total glucan synthesis activity was measured as the conversion of the glucosyl moiety of [glucose- $6{ }^{-3} \mathrm{H}$ ] sucrose to methanol-insoluble glucan (17). The standard reaction mixture consisted of $10 \mathrm{mM}$ [glucose- $6{ }^{3} \mathrm{H}$ ] sucrose $(50$ $\mathrm{mCi} / \mathrm{mol}[1.85 \mathrm{GBq} / \mathrm{mol}])(10 \mu \mathrm{l})$ and GTF $(5 \mu \mathrm{l})$ in a total volume of $20 \mu \mathrm{lo}$ $0.1 \mathrm{M}$ potassium phosphate buffer (KPB) $(\mathrm{pH} 6.0)$. The reaction mixtures were incubated for $1 \mathrm{~h}$ at $37^{\circ} \mathrm{C}$, and the samples were spotted onto filter paper ( 1 by $1.5 \mathrm{~cm}$ ). The filter papers were washed three times with methanol, dried, and immersed in scintillation fluid to determine the amount of $\left[{ }^{3} \mathrm{H}\right] \mathrm{glucose}$ incorporated into the total glucan synthesized. One unit of GTF activity is defined as the amount of enzyme required to incorporate $1.0 \mu \mathrm{mol}$ of glucose residues from the sucrose molecule into glucan per min under the conditions described above. To evaluate water-soluble and water-insoluble glucan synthesis activities, $1 \mathrm{ml}$ of reaction mixture containing $10 \mathrm{mM}$ [glucose- $-6{ }^{-3} \mathrm{H}$ ] sucrose in $0.1 \mathrm{M} \mathrm{KPB}(\mathrm{pH} 6.0)$ and $50 \mathrm{mU}$ of GTF $(250 \mu \mathrm{l})$ was incubated for $18 \mathrm{~h}$ at $37^{\circ} \mathrm{C}$. After incubation, the reaction mixture was centrifuged at $1,600 \times g$ for $15 \mathrm{~min}$ at $4^{\circ} \mathrm{C}$. An aliquot $(50$ $\mu \mathrm{l})$ of the supernatant was removed, spotted on filter papers, and washed three times with methanol. The incorporated radioactivity was counted as water-soluble glucans. In addition, the precipitates were washed three times with distilled water, and the radioactivity of water-insoluble glucan was measured. To deter- 
mine the inhibitory effects of the antibodies against the fusion proteins on glucan synthesis, various amounts of purified IgG antibodies were added at the same time as the substrate into the reaction mixtures, and the glucan synthesis activities of GTFs were measured as described above.

Sucrose-independent and sucrose-dependent adhesion of $S$. mutans cells to S-HA. Whole paraffin-stimulated saliva was collected (on ice) from a healthy adult subject and clarified by centrifugation. The same source was used for all experiments. Spheroidal hydroxyapatite beads $(5 \mathrm{mg})$ (BDH, Poole, England) were incubated with $200 \mu \mathrm{l}$ of clarified human whole saliva for $1 \mathrm{~h}$ at $37^{\circ} \mathrm{C}$ and washed three times with buffered $\mathrm{KCl}(18)$. The S-HA beads were incubated with $0.1 \%$ (wt $/ \mathrm{vol}$ ) bovine serum albumin in buffered $\mathrm{KCl}$ for $1 \mathrm{~h}$ at $37^{\circ} \mathrm{C}$ to block nonspecific binding sites. S. mutans MT8148 was grown at $37^{\circ} \mathrm{C}$ for $18 \mathrm{~h}$ in BHI broth containing $\left[{ }^{3} \mathrm{H}\right]$ thymidine $(70.0 \mathrm{Ci} / \mathrm{mmol}[2.59 \mathrm{GBq} / \mathrm{mmol}])$ at a final concentration of $20 \mu \mathrm{Ci} / \mathrm{ml}$. $\left[{ }^{3} \mathrm{H}\right]$ thymidine-labeled bacteria $\left(2 \times 10^{7}\right)$ were allowed to react with S-HA beads $(5 \mathrm{mg})$ in the presence or absence of $10 \mathrm{mM}$ sucrose in $200 \mu \mathrm{l}$ of buffered $\mathrm{KCl}$. After incubation at $37^{\circ} \mathrm{C}$ for $3 \mathrm{~h}$, the beads were washed three times with buffered $\mathrm{KCl}$ and the radioactivity associated with the S-HA beads was determined. The number of bacteria adsorbed was determined from the calculated specific radioactivity of the bacteria. To evaluate the inhibitory effects of antibodies on the adherence of $S$. mutans cells to S-HA beads, $\left[{ }^{3} \mathrm{H}\right]$ thymidine-labeled bacteria $\left(2 \times 10^{7}\right)$ were allowed to react with S-HA beads $(5 \mathrm{mg})$ in $200 \mu \mathrm{l}$ of buffered $\mathrm{KCl}$ containing various amounts of IgG antibodies and sucrose $(0$ or $10 \mathrm{mM})$ at $37^{\circ} \mathrm{C}$ for $3 \mathrm{~h}$.

ELISA. For the enzyme-linked immunosorbent assay (ELISA), 96-well microtiter plates were coated with $100 \mu \mathrm{l}$ of rPAc or GTF-I $(5 \mu \mathrm{g} / \mathrm{ml})$ in $50 \mathrm{mM}$ carbonate-bicarbonate buffer $(\mathrm{pH} 9.6)$. After overnight incubation at $4^{\circ} \mathrm{C}$, the plates were washed with PBS containing $0.05 \%$ (vol/vol) Tween 20 (PBST) and blocked with PBST containing 1\% (wt/vol) bovine serum albumin. After the plates were washed three times with PBST, twofold serial dilutions of rabbit antisera were added ( $100 \mu \mathrm{l}$ per well) and the plates were incubated for $1 \mathrm{~h}$ at $37^{\circ} \mathrm{C}$. The bound antibodies were detected with alkaline phosphatase-conjugated anti-rabbit IgG (heavy and light chains) serum (Zymed Laboratories, South San Francisco, Calif.) followed by the addition of $p$-nitrophenylphosphate substrate solution $(1 \mathrm{mg} / \mathrm{ml})$. After $1 \mathrm{~h}$ of incubation at $37^{\circ} \mathrm{C}$, the $A_{405}$ was measured with a microplate reader (Bio-Rad Laboratories). The ELISA antibody titer was expressed as the $\log _{10}$ of the reciprocal of the highest dilution giving an $A_{405}$ of 0.2 above the conjugate control (no sample added) after $1 \mathrm{~h}$ of incubation with the substrate.

Antibody-induced aggregation. Whole cells of $S$. mutans MT8148 were suspended in PBS to an $A_{550}$ of 0.96 . Each solution $(100 \mu \mathrm{l})$ of purified IgG antibodies $(1 \mathrm{mg} / \mathrm{ml})$ was mixed with $0.9 \mathrm{ml}$ of the cell suspension, and the change of $A_{550}$ at $37^{\circ} \mathrm{C}$ was monitored for $3 \mathrm{~h}$ with a spectrophotometer equipped with a CPS-240A cell positioner (UV-2000; Shimatzu Co., Kyoto, Japan). The $A_{550}$ of the reaction mixture at time zero was approximately 0.92

SDS-PAGE and immunoblotting. SDS-PAGE was performed in $10 \%$ polyacrylamide gels by the method of Laemmli (21). Proteins were stained with Coomassie brilliant blue R-250. The cell lysates from E. coli strains expressing the fusion proteins, the purified fusion proteins, rPAc, PAcA, GTF-I, GTF-I-GB, and GTF-I-SB were subjected to SDS-PAGE and electrophoretically transferred to a nitrocellulose membrane. The membrane was treated with rabbit antibodies raised against rPAc, GTF-I, PAcA-GB, or PAcA-SB. The antibodies bound to proteins immobilized on the membrane were detected with alkaline phosphatase-conjugated goat anti-rabbit immunoglobulins.

Statistical analysis. Differences in the glucan synthesis and the adhesion of $S$. mutans to S-HA between control and test samples were determined by Student's $t$ test.

\section{RESULTS}

Purification of PAc-GTF fusion proteins and preparation of rabbit antibodies against the fusion proteins. We have constructed two plasmids, pQEPG22 and pQEPG23, encoding the A region of PAc fused to the GB domain of GTF-I and the A region of PAc fused to the SB domain of GTF-I, respectively (Fig. 1). Cell lysates prepared from E. coli XL1-Blue cells harboring the pQEPG22 plasmid contained a fusion protein, PAcA-GB, which migrated at approximately $80 \mathrm{kDa}$ (the size of pacA-gtfB-GB is $2.2 \mathrm{~kb}$ ) on SDS-PAGE gels (Fig. 2). Cell lysates from $E$. coli XL1-Blue harboring the pQEPG23 plasmid contained a fusion protein, PAcA-SB, which migrated at approximately $62 \mathrm{kDa}$ (the size of pacA-gtfB-SB is $1.7 \mathrm{~kb}$ ) on SDS-PAGE gels. A single protein band was obtained from each cell lysate by a one-step purification with Ni-nitrilotriacetic acid resin (Fig. 2). Approximately $6 \mathrm{mg}$ of purified fusion protein was obtained from each liter of E. coli cultures. The purified fusion proteins specifically reacted with both rabbit anti-rPAc serum and rabbit anti-GTF-I serum upon immuno-

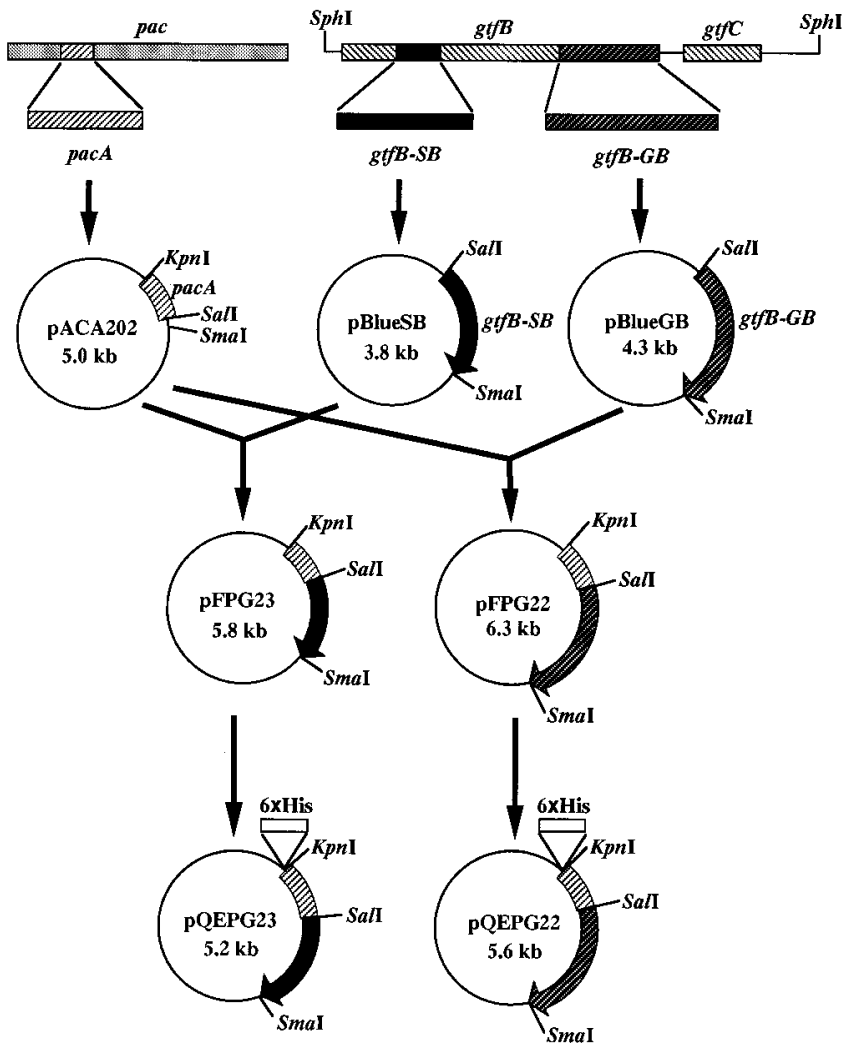

FIG. 1. Summary of genetic fusion of the SB domain or GB domain of GTF-I to the A region (PAcA) of PAc. The pacA (bp 598 to 1443 of the pac gene), gtfB-SB (bp 796 to 1587 of the gtfB gene), and gtfB-GB (bp 3245 to 4425 of the $g t f B$ gene and its 226-bp downstream region) gene fragments were cloned from chromosomal DNA of $S$. mutans MT8148 as described in Materials and Methods. The fragment $\operatorname{tg} B-S B$ or gtfB-GB was fused to the $3^{\prime}$ end of $p a c A$ to construct the fusion gene $p a c A-S B$ or $p a c A-G B$, respectively. The pacA-SB and pacA-GB gene fusions were inserted as a KpnI-SmaI fragment into the expression vector $\mathrm{pQE}-30$. The expression vectors contain the DNA fragments encoding the amino acid sequences of a six-histidine tag and the PAcA-GB or PAcA-SB fusion protein.

blotting (data not shown). Rabbit IgG antibodies raised against the fusion protein PAcA-GB showed reactivity with $\mathrm{rPAc}$, the PAcA polypeptide, GTF-I, GTF-I-GB, and the two fusion proteins but did not react with GTF-I-SB (Fig. 3). Conversely, rabbit $\mathrm{IgG}$ antibodies against the fusion protein $\mathrm{PAcA}-\mathrm{SB}$ reacted with rPAc, PAcA, GTF-I, GTF-I-SB, and the fusion proteins but did not react with GTF-I-GB. Table 2 shows ELISA titers of rabbit $\mathrm{IgG}$ antibodies to rPAc and GTF-I. Anti-PAcA-GB antibodies and anti-PAcA-SB antibodies exhibited similar ELISA titers to rPAc, while the titer of antiPAcA-GB antibodies to GTF-I was slightly higher than that of anti-PAcA-SB antibodies.

Antibody-induced aggregation. Rabbit IgG antibodies against rPAc and PAcA-GB induced strong aggregation of $S$. mutans, while anti-PAcA-SB IgG antibodies and anti-GTF-I IgG antibodies induced moderate aggregation of $S$. mutans cells (Fig. 4). The aggregation induced by anti-PAcA IgG antibodies was weak. Preimmune rabbit serum did not induce aggregation.

Inhibition of GTFs. The total glucan synthesis by cell-associated and cell-free GTF preparations from $S$. mutans MT8148 was markedly inhibited by the addition of rabbit IgG antibodies against PAcA-GB or GTF-I. However, rabbit IgG antibodies against PAcA-SB, rPAc, and PAcA and preimmune rabbit IgG showed no significant inhibition of glucan synthesis (Fig. 


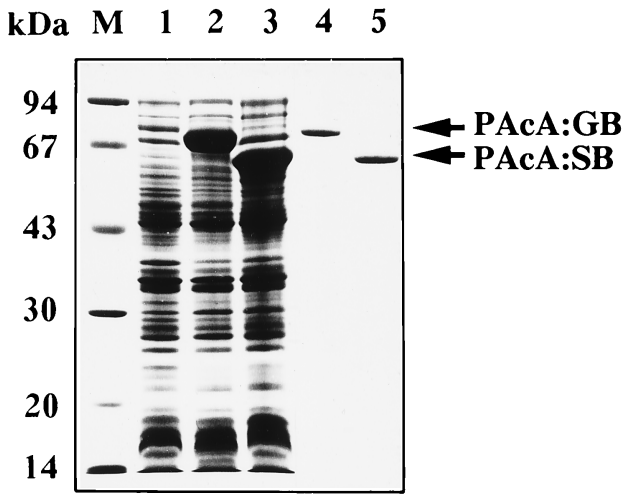

FIG. 2. Expression and purification of the fusion proteins. The crude cell lysates of $E$. coli XL1-Blue harboring the expression plasmids pQE-30, pQEPG22, and pQEPG23 and the purified fusion proteins were suspended in SDS-PAGE loading buffer and heated at $100^{\circ} \mathrm{C}$ for $5 \mathrm{~min}$. Samples were then subjected to SDS-PAGE (10\% polyacrylamide), and the gel was stained with Coomassie brilliant blue. Lane M, molecular mass markers; lane 1, cell lysate $(25 \mu \mathrm{g})$ of $E$. coli harboring pQE-30; lane 2, cell lysate $(25 \mu \mathrm{g})$ of $E$. coli harboring pQEPG22; lane 3, cell lysate $(25 \mu \mathrm{g})$ of $E$. coli harboring pQEPG23; lane 4, purified PAcA-GB $(2 \mu \mathrm{g})$; lane 5, purified PAcA-SB $(2 \mu \mathrm{g})$.

5). Antibodies against PAcA-SB enhanced the glucan synthesis by cell-free GTF of $S$. mutans MT8148. Similar results were obtained with sera from two other rabbits immunized with the fusion protein PAcA-SB (data not shown).

To determine whether antibodies against the fusion proteins PAcA-GB and PAcA-SB have any effect on the water solubility of the synthesized glucan polymers, the amounts of waterinsoluble and water-soluble glucans were differentially quantitated. Anti-PAcA-GB IgG antibodies and anti-GTF-I IgG antibodies exhibited inhibitory effects on the synthesis of watersoluble and water-insoluble glucans by both the cell-associated and cell-free GTF preparations from $S$. mutans MT8148, but the water-soluble glucan synthesis was only weakly inhibited (Fig. 6). Anti-PAcA-SB IgG antibodies did not inhibit the water-insoluble glucan synthesis catalyzed by the cell-associated and cell-free GTF preparations. Further experiments were performed with three GTF preparations obtained from

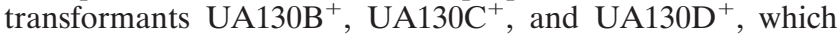
express a single type of GTF (GTF-I, GTF-SI, and GTF-S, respectively). Anti-PAcA-GB IgG antibodies and anti-GTF-I IgG antibodies markedly inhibited glucan synthesis by GTF-I

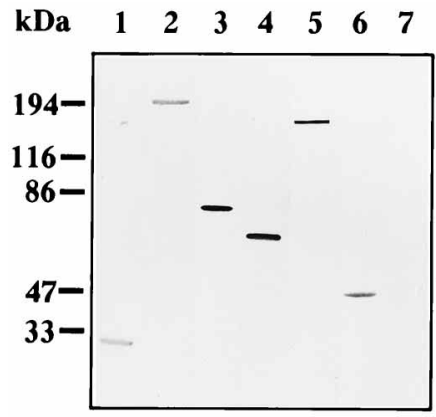

Anti-PAcA:GB

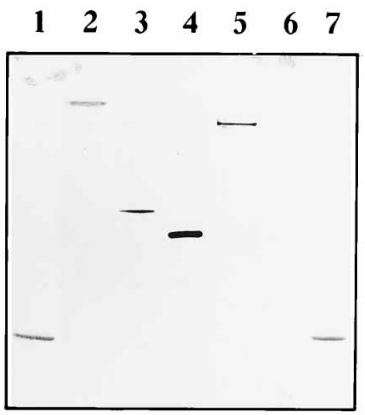

Anti-PAcA:SB
FIG. 3. Specificity of rabbit IgG antibodies against fusion proteins. Purified samples $(1 \mu \mathrm{g}$ each) were subjected to SDS-PAGE (10\% polyacrylamide) and then electrophoretically transferred to nitrocellulose membranes. The membranes were reacted with rabbit IgG antibodies raised against the fusion proteins PAcA-GB and PAcA-SB. Lanes 1, PAcA; lanes 2, rPAc; lanes 3, PAcA-GB; lanes 4, PAcA-SB; lanes 5, GTF-I; lanes 6, GTF-I-GB; lanes 7, GTF-I-SB.
TABLE 2. ELISA titers of rabbit serum IgG antibodies to rPAc and GTF- ${ }^{a}$

\begin{tabular}{lcc}
\hline \multirow{2}{*}{ Antibody } & \multicolumn{2}{c}{$\begin{array}{c}\text { ELISA antibody titer with } \\
\text { coating antigen }^{b} \text { : }\end{array}$} \\
\cline { 2 - 3 } & rPAc & GTF-I \\
\hline Anti-PAcA-GB & $5.10 \pm 0.75$ & $4.01 \pm 0.49$ \\
Anti-PAcA-SB & $4.95 \pm 0.60$ & $3.60 \pm 0.56$ \\
Anti-rPAc & $5.78 \pm 0.81$ & $<0.90$ \\
Anti-PAcA & $4.08 \pm 0.33$ & $<0.90$ \\
Anti-GTF-I & $<0.90$ & $4.71 \pm 0.73$ \\
Preimmune IgG & $<0.90$ & $<0.90$ \\
\hline
\end{tabular}

${ }^{a}$ ELISA antibody titer expressed as $\log _{10}$ of the reciprocal of the highest dilution giving an $A_{405}$ of 0.2 above the conjugated control (no sample added) after $1 \mathrm{~h}$ of incubation with the substrate.

${ }^{b}$ Values are reported as the means \pm standard deviations of triplicate assays.

but only moderately inhibited glucan synthesis by GTF-SI (Table 3). Anti-PAcA-GB antibodies weakly inhibited glucan synthesis by GTF-S, but anti-GTF-I antibodies did not. AntiPAcA-SB antibodies and preimmune IgG enhanced glucan synthesis catalyzed by all three GTFs.

Inhibition of bacterial adhesion to S-HA. The effect of $\mathrm{IgG}$ antibodies on the sucrose-independent adhesion of $S$. mutans MT8148 to S-HA beads was examined. IgG antibodies against rPAc, PAcA, PAcA-GB, and PAcA-SB showed strong inhibition of the sucrose-independent adhesion of $S$. mutans cells (Table 4). IgG antibodies against GTF-I weakly suppressed the sucrose-independent adhesion. On the other hand, the sucrose-dependent adhesion of $S$. mutans to S-HA was significantly inhibited by the addition of anti-PAcA-GB IgG antibodies and anti-GTF-I IgG antibodies but not by the addition of

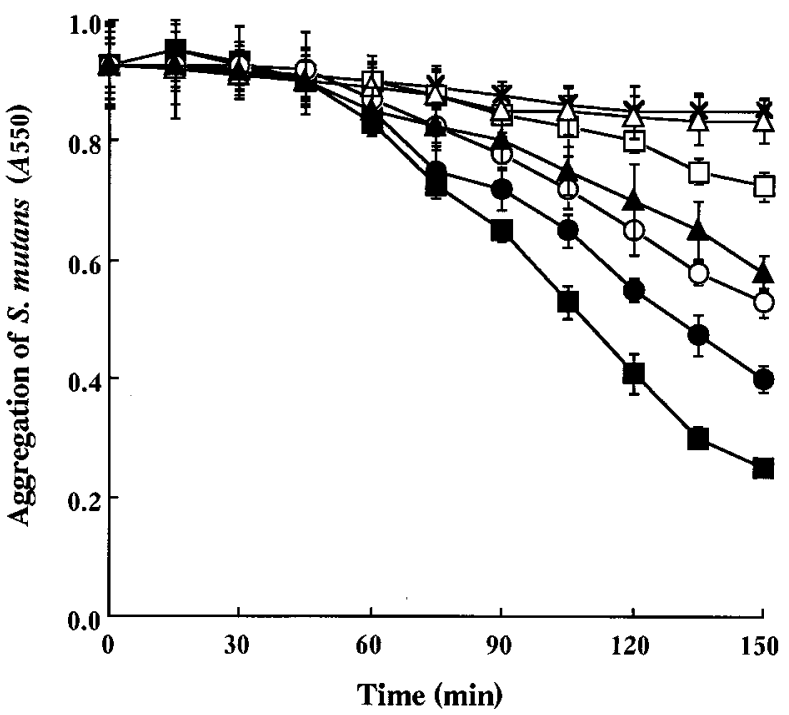

FIG. 4. Antibody-induced aggregation of $S$. mutans cells. Whole cells of $S$. mutans MT8148 grown in BHI broth were harvested and suspended in PBS. The $A_{550}$ was adjusted with PBS to 0.96 . Each solution $(100 \mu \mathrm{l})$ of the purified antibodies $(1 \mathrm{mg} / \mathrm{ml})$ was mixed with $0.9 \mathrm{ml}$ of the cell suspension, and the antibody-induced aggregation was measured as described in Materials and Methods. Values are reported as the means \pm standard deviations of triplicate assays. The experiments were performed twice, and similar results were obtained in both experiments. Symbols: @, anti-PAcA-GB IgG antibodies; $\bigcirc$, anti-PAcA-SB IgG antibodies; $\boldsymbol{\square}$, anti-rPAc IgG antibodies; $\square$, anti-PAcA IgG antibodies; $\boldsymbol{\Lambda}$, antiGTF-I IgG antibodies; $\triangle$, pre-immune IgG; $\times$, control (no addition of antibodies). 


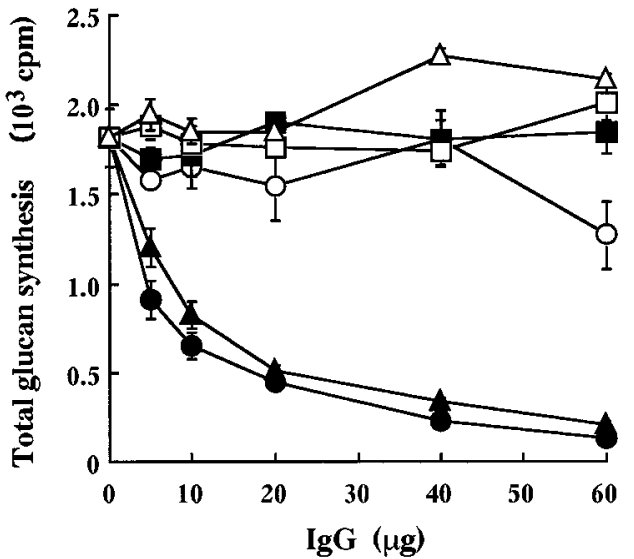

B.

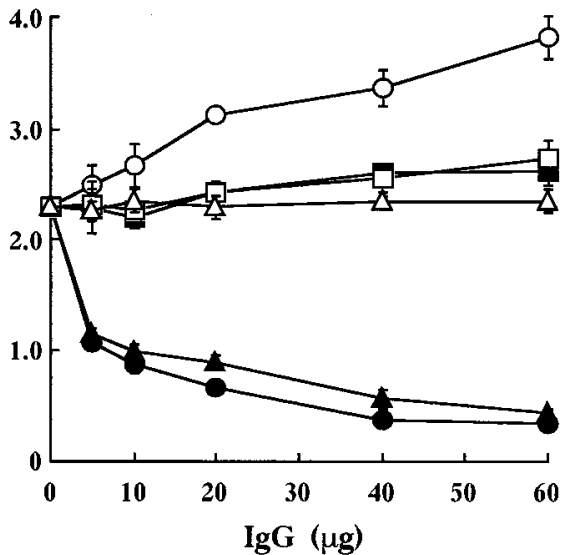

FIG. 5. Effects of IgG antibodies against PAcA-GB, PAcA-SB, rPAc, PAcA, and GTF-I on the glucan synthesis catalyzed by crude GTF preparations from $S$ mutans MT8148. (A) Cell-associated GTF; (B) cell-free GTF. The reaction mixture consisted of $10 \mathrm{mM}$ [glucose-6- $\left.{ }^{3} \mathrm{H}\right] \mathrm{sucrose}$, crude GTF preparation (ca. $0.5 \mathrm{mU}$ ) from $S$. mutans MT8148, and rabbit $\mathrm{IgG}$ antibodies $(0$ to $60 \mu \mathrm{g}$ of protein) in a total volume of $20 \mu \mathrm{l}$ of $0.1 \mathrm{M} \mathrm{KPB}$ (pH 6.0$)$. After incubation for $1 \mathrm{~h}$ at $37^{\circ} \mathrm{C}$, the total amount of glucan synthesized was measured. Values are reported as the means \pm standard deviations of triplicate assays. The experiments were performed three times, and similar results were obtained in each experiment. Symbols: $\bullet$, anti-PAcA-GB IgG antibodies; $\bigcirc$, anti-PAcA-SB IgG antibodies; $\mathbf{\square}$, anti-rPAc IgG antibodies; $\square$, anti-PAcA IgG antibodies; $\boldsymbol{\Delta}$, anti-GTF-I antibodies; $\triangle$, preimmune IgG.

IgG antibodies against rPAc, PAcA-SB, and PAcA and preimmune IgG (Table 4).

\section{DISCUSSION}

Fusion proteins of multiple virulence factors may be useful for the immunological prevention of various infectious diseases. For mucosal immunization against dental caries, fusion proteins consisting of the GTF-I fragment and the cholera toxin $\mathrm{B}$ subunit $(8,22)$ (the latter is known as a potent mucosal adjuvant) and a fusion protein consisting of the A region of PAc and the cholera toxin B subunit (11) have been genetically constructed. These fusion proteins lead to the inhibition of one of the colonization factors. In the present study, we have constructed a new fusion protein, PAcA-GB, consisting of the functional domains of two major colonization factors of $S$. mutans. Antibodies raised against the fusion protein strongly inhibit the sucrose-independent initial attachment and sucrose-dependent cellular accumulation of $S$. mutans on artificial acquired pellicles.

Immunization with PAc (I/II or B) of $S$. mutans protects monkeys against dental caries $(24,29,30)$. However, PAc (SR) has common epitopes with human $\mathrm{IgG}$, and high titers of anti-human $\mathrm{IgG}$ antibodies cross-reactive with the streptococcal protein antigen are observed in sera from patients with rheumatic disease $(9,25)$. The domain specifying the human IgG cross-reactive epitope(s) is located along the C-terminal two-thirds of the PAc (SR) protein (9). It is possible that the epitope(s) could lead to the induction of natural anti-IgG antibodies. Therefore, we used the A region, located in the $\mathrm{N}$ terminus, as an immunogen in the present study.

The PAc protein of $S$. mutans participates in the hydrophobic interaction between the organism and acquired pellicles on tooth surfaces $(18,23)$. Several investigators $(4,7,12,27)$ have shown that the salivary glycoprotein binding domain is located in the $\mathrm{N}$ terminus of the PAc molecule. On the other hand, Munro et al. (26) and Kelly et al. (16) have indicated that an adhesin binding activity resides within the portion of the PAc (I/II) protein comprising residues 816 to 1213 . In this study, antibodies against the A-region fragment partially inhibited the sucrose-independent adhesion of $S$. mutans to S-HA, suggesting that multiple saliva binding regions may exist on the PAc molecule.

Although anti-PAc antibodies markedly suppressed the adhesion of $S$. mutans to S-HA in the absence of sucrose, the antibodies did not inhibit the sucrose-dependent adhesion of the organism. In this regard, Bowen et al. (3) reported that $S$. mutans NG8 and its $\mathrm{PAc}(\mathrm{P} 1)$-defective mutant alike readily colonize rats fed a highly cariogenic diet containing $56 \%$ sucrose and cause similar levels of smooth surface caries under these dietary conditions. These findings suggest that $S$. mutans

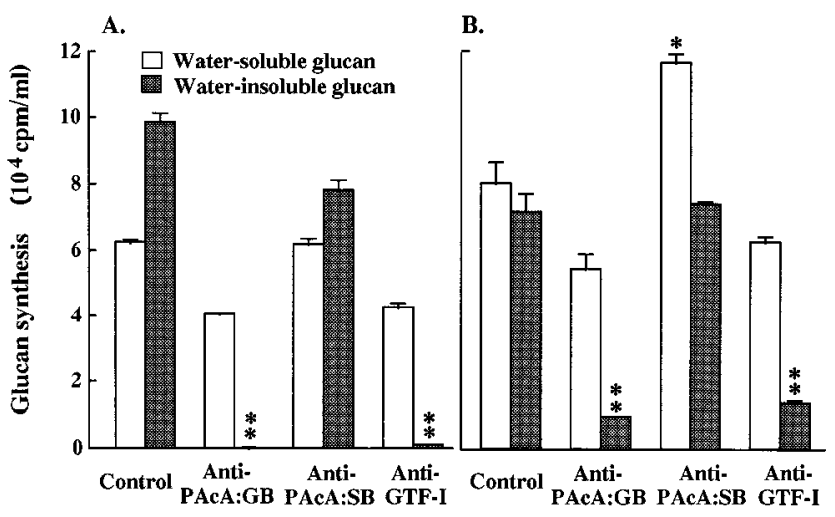

FIG. 6. Effects of antibodies against fusion proteins on water-soluble and water-insoluble glucan synthesis catalyzed by crude GTF preparations from $S$. mutans MT8148. (A) Cell-associated GTF; (B) cell-free GTF. The reaction mixture consisted of $10 \mathrm{mM}$ [glucose- $6-{ }^{3} \mathrm{H}$ ] sucrose, crude GTF preparation (50 $\mathrm{mU}$ ) from $S$. mutans MT8148, and 0 (control) or $100 \mu \mathrm{g}$ of purified IgG antibodies in a total volume of $1 \mathrm{ml}$ of $0.1 \mathrm{M} \mathrm{KPB}(\mathrm{pH} \mathrm{6.0)}$ ). After incubation for $18 \mathrm{~h}$ at $37^{\circ} \mathrm{C}$, the amount (counts per minute) of water-soluble and water-insoluble glucan synthesized was differentially determined as described in Materials and Methods. Values are reported as the means \pm standard deviations of triplicate assays. The experiments were performed three times, and similar results were obtained in each experiment. Single asterisk, $P<0.01$; double asterisk, $P<0.001$ compared with control. 
TABLE 3. Inhibitory effects of anti-fusion protein antibodies on the glucan synthesis catalyzed by $S$. mutans GTFs $^{a}$

\begin{tabular}{lccc}
\hline \multirow{2}{*}{ Antibody } & \multicolumn{3}{c}{${\text { Glucan synthesis }(\mathrm{cpm})^{b}}$} \\
\cline { 2 - 4 } & $\mathrm{UA130B}^{+}$(cell-associated GTF) & $\mathrm{UA130C}^{+}$(cell-associated GTF) & UA130D $^{+}($cell-free GTF) \\
\hline Control & $2,378 \pm 126(100)$ & $2,265 \pm 224(100)$ & $2,320 \pm 157(100)$ \\
Anti-PAcA-GB & $88 \pm 20^{d}(3.7)$ & $1,095 \pm 101^{d}(48)$ & $1,831 \pm 63^{c}(79)$ \\
Anti-PAcA-SB & $2,643 \pm 127(111)$ & $2,880 \pm 13(127)$ & $3,096 \pm 194^{c}(133)$ \\
Anti-GTF-I & $243 \pm 35^{d}(10.2)$ & $1,163 \pm 72^{d}(51)$ & $2,630 \pm 163(113)$ \\
Preimmune IgG & $2,912 \pm 309^{c}(122)$ & $3,843 \pm 81^{d}(170)$ & $2,951 \pm 111^{c}(127)$ \\
\hline
\end{tabular}

${ }^{a}$ Each GTF preparation (ca. $0.5 \mathrm{mU}$ ) was allowed to react with $10 \mathrm{mM}$ [glucose-6- ${ }^{3} \mathrm{H}$ ]sucrose in the absence (control) or presence of purified rabbit IgG antibodies $(25 \mu \mathrm{g})$ in a total volume of $20 \mu \mathrm{l}$ of $0.1 \mathrm{M} \mathrm{KPB}(\mathrm{pH} 6.0)$ at $37^{\circ} \mathrm{C}$ for $1 \mathrm{~h}$. Values are reported as the means \pm standard deviations of triplicate assays. The experiments were performed three times, and similar results were obtained in each experiment.

${ }^{b}$ Transformants of $S$. mutans UA130. UA130B ${ }^{+}$, GTF-I-producing transformant; UA130C ${ }^{+}$, GTF-SI-producing transformant; UA130D ${ }^{+}$, GTF-S-producing transformant. Values in parentheses are percentages of the amounts of total glucan synthesized in the control (no addition of antibodies).

${ }^{c} P<0.05$ compared with control.

${ }^{d} P<0.01$ compared with control.

does not require PAc for colonization of the smooth surfaces of teeth in the presence of sucrose.

All three GTFs of $S$. mutans possess two functional domains, an SB domain in the N-terminal half of the GTF molecules and a repeated GB domain in the $\mathrm{C}$ termini of the enzymes. The GB domains of these GTFs have a high degree of homology with the ligand-binding C-terminal repeats of Clostridium difficile toxins (ToxA and ToxB) and Streptococcus pneumoniae lysins $(10,36)$. Chia et al. (5) demonstrated that monoclonal antibodies against a 19-mer peptide sequence (residues 435 to 453 of GTF-SI) within a highly conserved region located in the $\mathrm{N}$-terminal regions of the GTFs and containing the catalytic site inhibit the GTF-SI enzymatic activity. Smith et al. (34) and Laloi et al. (22) have also reported that sequences within the SB domain can induce GTF-inhibitory antibodies in rats and rabbits. In contrast, Cope and Mooser (6) reported that rabbit antibodies raised against peptides derived from an SB sequence common to the family of mutans streptococcus GTFs could not inhibit glucan synthesis by GTFs. Rabbit IgG antibodies against the fusion protein PAcA-SB, consisting of the PAcA fragment and the SB domain of GTF-I, also showed no significant inhibition of glucan synthesis catalyzed by any GTFs. As suggested by Cope and Mooser (6), it is possible that antibodies cannot access the catalytic site or that they do not recognize the native enzyme conformation. The lack of inhi-

TABLE 4. Inhibition of sucrose-independent and sucrosedependent adhesion of $S$. mutans to S-HA beads by rabbit $\mathrm{IgG}$ antibodies ${ }^{a}$

\begin{tabular}{lcc}
\hline \multirow{2}{*}{\multicolumn{1}{c}{ Antibody }} & \multicolumn{2}{c}{ No. of cells adhering to S-HA $\left(10^{6} \text { cells }\right)^{b}$} \\
\cline { 2 - 3 } & Without sucrose & With sucrose \\
\hline Control & $1.45 \pm 0.20$ & $2.33 \pm 0.43$ \\
Anti-PAcA-GB & $0.40 \pm 0.03^{c}$ & $0.54 \pm 0.09^{d}$ \\
Anti-PAcA-SB & $0.48 \pm 0.03^{c}$ & $3.20 \pm 0.43$ \\
Anti-rPAc & $0.23 \pm 0.04^{d}$ & $2.03 \pm 0.24$ \\
Anti-PAcA & $0.58 \pm 0.02^{c}$ & $3.66 \pm 0.70$ \\
Anti-GTF-I & $1.01 \pm 0.13^{c}$ & $0.72 \pm 0.08^{d}$ \\
Preimmune IgG & $1.32 \pm 0.11$ & $6.63 \pm 0.28^{d}$
\end{tabular}

${ }^{a}\left[{ }^{3} \mathrm{H}\right]$ thymidine-labeled $S$. mutans MT8148 cells $\left(2 \times 10^{7}\right)$ were allowed to react with $5 \mathrm{mg}$ of S-HA beads without (control) or with IgG antibodies (100 $\mu \mathrm{g}$ of protein) in the absence or presence of $10 \mathrm{mM}$ sucrose in $200 \mu \mathrm{l}$ of buffered $\mathrm{KCl}$.

${ }^{b}$ Values are reported as the means \pm standard deviations of triplicate assays. The experiments were performed three times, and similar results were obtained in each experiment.

${ }^{c} P<0.05$ compared with control.

${ }^{d} P<0.01$ compared with control. bition of glucan synthesis by rabbit antibodies raised against the fusion protein PAcA-SB, however, should be confirmed by studies using more rabbits, as the number of rabbits tested in this study is small. On the other hand, antibodies against the fusion protein PAcA-GB, consisting of the PAcA fragment and the GB domain of GTF-I, significantly inhibited glucan synthesis by GTF-I. In this regard, Taubman et al. (35) have shown that rat serum antibodies against a 22 -mer peptide corresponding to the amino acid sequence of the GB domain of Streptococcus downei GTF-I suppress the synthesis of watersoluble glucan by crude GTF enzyme from S. mutans and the synthesis of water-soluble and water-insoluble glucans by crude GTF enzyme from Streptococcus sobrinus.

In this study, rabbit preimmune $\operatorname{IgG}$ significantly enhanced both the glucan synthesis by GTFs and the sucrose-dependent adhesion of S. mutans (Tables 3 and 4). Similar findings have been reported for control and/or immune sera from rats, monkeys, and humans, as well as sera from rabbits (31). It is believed that phospholipids present in sera cause the observed stimulation of GTF activity (31).

The degree of inhibition of the sucrose-independent adhesion of $S$. mutans to S-HA by anti-PAcA-GB IgG antibodies or anti-PAcA-SB antibodies was slightly higher than that of the inhibition of the sucrose-independent adhesion by anti-PAcA antibodies (Table 4). The following possibilities are considered for this phenomenon. (i) Cell-associated GTF-I as well as PAc may participate in the sucrose-independent adhesion of $S$. $m u$ tans to S-HA. In fact, anti-GTF-I antibodies weakly inhibited the adhesion of the organism to S-HA in the absence of sucrose. (ii) Conformational changes in the PAcA fragment might occur. Immunization of rabbits with the fragment could not effectively induce antibodies against the functional site of PAc, but immunization with the fusion proteins or rPAc can induce such antibodies. The validity of these speculations, however, remains to be determined.

In conclusion, we have constructed a fusion protein consisting of the A region of PAc and the GB domain of GTF-I and demonstrated that rabbit antibodies raised against the fusion protein strongly suppress the glucan synthesis catalyzed by GTF-I from S. mutans as well as the in vitro colonization by the organism in the absence and presence of sucrose. Antibodies against this fusion protein may be applicable to the control of the colonization of teeth by $S$. mutans and to the prevention of dental caries.

\section{ACKNOWLEDGMENTS}

This study was supported in part by Grant-in-Aid for Scientific Research (A) 07557134 from the Ministry of Education, Science, 
Sports, and Culture of Japan (T.K.) and by the Uehara Memorial Foundation (T.K.).

We thank H. K. Kuramitsu for providing the gtfB gene of strain GS-5; pResAmpdFTFSp ${ }^{\text {r }}$; and transformants UA130B, UA130C, and UA130BC. We also thank S. Sato for providing rabbit antifructosyltransferase serum.

\section{REFERENCES}

1. Amann, E., B. Ochs, and K.-J. Abel. 1988. Tightly regulated tac promoter vectors useful for the expression of unfused and fused proteins in Escherichia coli. Gene 69:301-315.

2. Aoki, H., T. Shiroza, M. Hayakawa, S. Sato, and H. K. Kuramitsu. 1986. Cloning of a Streptococcus mutans glucosyltransferase gene coding for insoluble glucan synthesis. Infect. Immun. 53:587-594.

3. Bowen, W. H., K. Schilling, E. Giertsen, S. Pearson, S. F. Lee, A. Bleiweis, and D. Beeman. 1991. Role of a cell surface-associated protein in adherence and dental caries. Infect. Immun. 59:4606-4609.

4. Brady, L. J., D. A. Piacentini, P. J. Crowley, P. C. F. Oyston, and A. S Bleiweis. 1992. Differentiation of salivary agglutinin-mediated adherence and aggregation of mutans streptococci by use of monoclonal antibodies against the major surface adhesin P1. Infect. Immun. 60:1008-1017.

5. Chia, J.-S., R.-H. Lin, S.-W. Lin, J.-Y. Chen, and C.-S. Yang. 1993. Inhibition of glucosyltransferase activities of Streptococcus mutans by a monoclonal antibody to a subsequence peptide. Infect. Immun. 61:4689-4695.

6. Cope, P. A., and G. Mooser. 1993. Antibodies against active-site peptides common to glucosyltransferases of mutans streptococci. Infect. Immun. 61: 4814-4817.

7. Crowley, P. J., L. J. Brady, D. A. Piacentini, and A. S. Bleiweis. 1993. Identification of a salivary agglutinin-binding domain within cell surface adhesin P1 of Streptococcus mutans. Infect. Immun. 61:1547-1552.

8. Dertzbaugh, M. T., and C. O. Elson. 1993. Comparative effectiveness of the cholera toxin B subunit and alkaline phosphatase as carriers for oral vaccines. Infect. Immun. 61:48-55.

9. Gangloff, S., R. M'Zoughi, E. Lett, M. Schöller, J. Baer, A. Pini, J. Ogier, and J.-P. Klein. 1992. Epitope mapping of Streptococcus mutans SR protein and human IgG cross-reactive determinants, by using recombinant proteins and synthetic peptides. J. Immunol. 148:3249-3255.

10. Giffard, P. M., and N. A. Jacques. 1994. Definition of a fundamental repeating unit in streptococcal glucosyltransferase glucan-binding regions and related sequences. J. Dent. Res. 73:1133-1141.

11. Hajishengallis, G., S. K. Hollingshead, T. Koga, and M. W. Russell. 1995. Mucosal immunization with a bacterial protein antigen genetically coupled to cholera toxin A2/B subunits. J. Immunol. 154:4322-4332.

12. Hajishengallis, G., T. Koga, and M. W. Russell. 1994. Affinity and specificity of the interactions between Streptococcus mutans antigen I/II and salivary components. J. Dent. Res. 73:1493-1502.

13. Hamada, S., T. Horikoshi, T. Minami, N. Okahashi, and T. Koga. 1989. Purification and characterization of cell-associated glucosyltransferase synthesizing water-insoluble glucan from serotype c Streptococcus mutans. J. Gen. Microbiol. 135:335-344.

14. Hanada, N., and H. K. Kuramitsu. 1989. Isolation and characterization of the Streptococcus mutans gtfD gene, coding for primer-dependent soluble glucan synthesis. Infect. Immun. 57:2079-2085.

15. Kelly, C., P. Evans, L. Bergmeier, S. F. Lee, A. Progulske-Fox, A. C. Harris, A. Aitken, A. S. Bleiweis, and T. Lehner. 1989. Sequence analysis of the cloned streptococcal cell surface antigen I/II. FEBS Lett. 258:127-132.

16. Kelly, C. G., S. Todryk, H. L. Kendal, G. H. Munro, and T. Lehner. 1995. T-cell, adhesion, and B-cell epitopes of the cell surface Streptococcus mutans protein antigen I/II. Infect. Immun. 63:3649-3658.

17. Koga, T., H. Asakawa, N. Okahashi, and S. Hamada. 1986. Sucrose-dependent cell adherence and cariogenicity of serotype c Streptococcus mutans. J. Gen. Microbiol. 132:2873-2883.

18. Koga, T., N. Okahashi, I. Takahashi, T. Kanamoto, H. Asakawa, and M. Iwaki. 1990. Surface hydrophobicity, adherence, and aggregation of cell surface protein antigen mutants of Streptococcus mutans serotype c. Infect. Immun. 58:289-296.

19. Koga, T., Y. Yamashita, Y. Nakano, M. Kawasaki, T. Oho, H. Yu, M. Nakai, and N. Okahashi. 1995. Surface proteins of Streptococcus mutans. Dev. Biol. Stand. 85:363-369.

20. Kuramitsu, H. K., M. Smorawinska, Y. J. Nakano, A. Shimamura, and M. Lis. 1995. Analysis of glucan synthesis by Streptococcus mutans. Dev. Biol. Stand. 85:303-307.

21. Laemmli, U. K. 1970. Cleavage of structural proteins during the assembly of the head of bacteriophage T4. Nature (London) 227:680-685.

22. Laloi, P., C. L. Munro, K. R. Jones, and F. L. Macrina. 1996. Immunologic characteristics of a Streptococcus mutans glucosyltransferase B sucrose-binding site peptide-cholera toxin B-subunit chimeric protein. Infect. Immun. 64:28-36.

23. Lee, S. F., A. Progulske-Fox, G. W. Erdos, D. A. Piacentini, G. Y. Ayakawa, P. J. Crowley, and A. S. Bleiweis. 1989. Construction and characterization of isogenic mutants of Streptococcus mutans deficient in major surface protein antigen P1 (I/II). Infect. Immun. 57:3306-3313.

24. Lehner, T., J. K.-C. Ma, G. Munro, P. Walker, A. Childerstone, S. Todryk, H. Kendal, and C. G. Kelly. 1994. T-cell and B-cell epitope mapping and construction of peptide vaccines, p. 279-292. In R. Genco, S. Hamada, T. Lehner, J. McGhee, and S. Mergenhagen (ed.), Molecular pathogenesis of periodontal disease. ASM Press, Washington, D.C.

25. Moisset, A., N. Schatz, Y. Lepoivre, S. Amadio, D. Wachsmann, M. Schöller, and J.-P. Klein. 1994. Conservation of salivary glycoprotein-interacting and human immunoglobulin G-cross-reactive domains of antigen I/II in oral streptococci. Infect. Immun. 62:184-193.

26. Munro, G. H., P. Evans, S. Todryk, P. Bukett, C. G. Kelly, and T. Lehner 1993. A protein fragment of streptococcal cell surface antigen I/II which prevents adhesion of Streptococcus mutans. Infect. Immun. 61:4590-4598.

27. Nakai, M., N. Okahashi, H. Ohta, and T. Koga. 1993. Saliva-binding region of Streptococcus mutans surface protein antigen. Infect. Immun. 61:43444349

28. Okahashi, N., C. Sasakawa, M. Yoshikawa, S. Hamada, and T. Koga. 1989 Molecular characterization of a surface protein antigen gene from serotype c Streptococcus mutans, implicated in dental caries. Mol. Microbiol. 3:673678.

29. Russell, M. W. 1992. Immunization against dental caries. Curr. Opin. Dent. 2:72-80.

30. Russell, R. R. B. 1994. The application of molecular genetics to the microbiology of dental caries. Caries Res. 28:69-82.

31. Schachtele, C. F, S. K. Harlander, J. W. Bracke, L. C. Ostrum, J.-A. B. Maltais, and R. J. Billings. 1978. Streptococcus mutans dextransucrase: stimulation by phospholipids from human sera and oral fluids. Infect. Immun. 22:714-720.

32. Shiroza, T., and H. K. Kuramitsu. 1993. Construction of a model secretion system for oral streptococci. Infect. Immun. 61:3745-3755.

33. Shiroza, T., S. Ueda, and H. K. Kuramitsu. 1987. Sequence analysis of the gtfB gene from Streptococcus mutans. J. Bacteriol. 169:4263-4270.

34. Smith, D. J., M. A. Taubman, W. F. King, S. Eida, J. R. Powell, and J. Eastcott. 1994. Immunological characteristics of a synthetic peptide associated with a catalytic domain of mutans streptococcal glucosyltransferase. Infect. Immun. 62:5470-5476.

35. Taubman, M. A., C. J. Holmberg, and D. J. Smith. 1995. Immunization of rats with synthetic peptide constructs from the glucan-binding or catalytic region of mutans streptococcal glucosyltransferase protects against dental caries. Infect. Immun. 63:3088-3093.

36. Von Eichel-Streiber, C., M. Sauerborn, and H. K. Kuramitsu. 1992. Evidence for a modular structure of the homologous repetitive C-terminal carbohydrate-binding sites of Clostridium difficile toxins and Streptococcus mutans glucosyltransferases. J. Bacteriol. 174:6707-6710.

37. Yamashita, Y., W. H. Bowen, R. A. Burne, and H. K. Kuramitsu. 1993. Role of the Streptococcus mutans gtf genes in caries induction in the specificpathogen-free rat model. Infect. Immun. 61:3811-3817.

Editor: J. R. McGhee 